\title{
Patient-specific tracer activity in MPI SPECT: A hands-on approach
}

\author{
J. D. van Dijk, MSc, ${ }^{a, d}$ P. L. Jager, PhD, $M D,{ }^{a} J$. P. Ottervanger, PhD, $M D,{ }^{b}$ \\ C. H. Slump, PhD, ${ }^{d}$ S. Knollema, MSc, MD, PhD, a and J. A. van Dalen, $\mathrm{PhD}^{\mathrm{c}}$ \\ a Department of Nuclear Medicine, Isala Hospital, Zwolle, The Netherlands \\ ${ }^{\mathrm{b}}$ Department of Cardiology, Isala Hospital, Zwolle, The Netherlands \\ c Department of Medical Physics, Isala Hospital, Zwolle, The Netherlands \\ d MIRA Institute for Biomedical Technology and Technical Medicine, University of Twente, \\ Enschede, The Netherlands
}

Received Aug 7, 2015; accepted Aug 27, 2015

doi:10.1007/s12350-015-0286-1

\section{See related article, pp. 134-142}

\section{INTRODUCTION}

Previously, several studies have reported that a decreasing image quality in heavier patients in myocardial perfusion imaging (MPI) using single-photon emission computed tomography (SPECT) can be compensated by using a body-weight-dependent tracer activity or scan time, ${ }^{1-3}$ as illustrated in Figure 1. Although we derived and validated a activity-scan-time formula for a conventional SPECT scanner, this formula cannot simply be used for all SPECT scanners. ${ }^{1}$ Differences in detector sensitivity, technical specifications such a collimator design and geometrical detector configuration, and acquisition and reconstruction settings limit the generalizability of the derived formula. Ideally, a tracer activity-scan-time formula should therefore be derived for each SPECT scanner using the method as described previously. ${ }^{1}$ However, this could be technically challenging and is time consuming. In this technical note, we therefore introduce, as a first-order approach, an alternative simplified method to obtain a body-weight-dependent protocol, which can easily be adopted in every day patient care.

Reprint requests: J. D. van Dijk, MSc, Department of Nuclear Medicine, Isala Hospital, Zwolle, The Netherlands; jorisvdijk@ gmail.com J Nucl Cardiol 2016;23:145-8.

$1071-3581 / \$ 34.00$

Copyright $\odot 2015$ The Author(s). This article is published with open access at Springerlink.com

\section{DERIVING A BODY-WEIGHT-DEPENDENT PROTOCOL}

In cardiac SPECT, the application of a fixed tracer activity and scan-time protocol results in a decreasing number of photon counts in heavier patients due to increased photon attenuation, as demonstrated earlier ${ }^{1,3}$ and illustrated in Figure 2A, D. As image quality primarily depends on the number of measured photon counts, a constant number of detected photon counts provides an image quality less dependent on patients' size. ${ }^{1,3}$

A patient-specific protocol will allow obtaining a constant number of detected photons independent of patients' size. ${ }^{1,3}$ A method to derive such a protocol is described recently. ${ }^{1}$ Ideally, the derivation and validation of a patient-specific protocol are performed for each SPECT scanner to account for differences in hardware, software, and acquisition and reconstruction settings. However, to limit the burden of using this extended method, we hereby introduce an alternative, simplified approach, which can easily be adopted in every day patient care. In this approach, we assume that local physicians consider their SPECT image quality of patients with average body weight, AVGweight, to be adequate, using the local tracer activity and scan-time combination. To convert this to other patients, a multiplication factor (MF) can be determined using

$$
\begin{aligned}
\mathrm{MF}= & \frac{0.13}{\mathrm{AVG}_{\text {weight }} 0.64} \times \text { body weight }(\mathrm{kg})+1-0.13 \\
& \times \mathrm{AVG}_{\text {weight }}{ }^{0.36} .
\end{aligned}
$$

This formula is derived from the validated tracer activity and scan-time formula as presented in our recent study by normalizing it to an average patient. ${ }^{1}$ In a 
patient population with an average body weight of $80 \mathrm{~kg}$, the MF formula can be described by

$$
\mathrm{MF}=\text { body weight }(\mathrm{kg}) \times 0.0079+0.37
$$

In the next step, the body-weight-specific tracer activity or scan time can be calculated using

Patient-specific tracer activity (using a fixed scan time)

$$
=\text { standard activity } \times \text { MF }
$$

Patient-specific scan time (using a fixed tracer activity)

$$
=\text { standard scan time } \times \text { MF }
$$

As can be seen, MF is 1.0 for a patient of $80 \mathrm{~kg}$ when applying Eq. 1b. In that case, the patient-specific tracer activity (or scan time) is the same as the standard administered activity (or scan time). For heavier patients MF is higher than 1, and for less heavy patients it is lower than 1. Table 1 shows an example with the outcome of these equations in practice. The suggested MF is only eligible for conventional SPECT cameras ${ }^{1}$ and patients weighing between 60 and $130 \mathrm{~kg}$, as weights outside this range were not used in deriving the formula. ${ }^{1}$ One could worry that the application of a patient-specific tracer activity or scan-time protocol deviates from the current guidelines. ${ }^{4,5}$ However, these guidelines are relatively old and partly outdated due to technological advances and revised insights. Motivated deviation can therefore be justified.

\section{BENEFICIAL EFFECT OF PATIENT-SPECIFIC TRACER ACTIVITIES}

Introducing a body-weight-dependent protocol will not only result in image quality that depends less on patients' size, it also allows for a reduction in the administered activity and, hence, radiation dose to the patient, as shown in a previous study ${ }^{6}$ and illustrated in Figure 2C, F. Nowadays, leaner patients are generally administered a higher activity than clinically necessary. In heavier patients, the currently applied fixed tracer activity is generally low or at best just sufficient. Implementing a patient-specific protocol will therefore result in a better image quality independent of patients' size. It might even allow an overall tracer activity or scan-time reduction, without compromising diagnostic accuracy.

\section{LOGISTICS OF A PATIENT-SPECIFIC TRACER ACTIVITY OR SCAN TIME}

A schematic overview of the required planning and actions when applying a patient-specific tracer activity or scan-time protocol is shown in Figure 3. Two additional actions are required as compared to the fixed tracer activity era. First, patients' body weight is always required for planning and should be stated on the requisition or
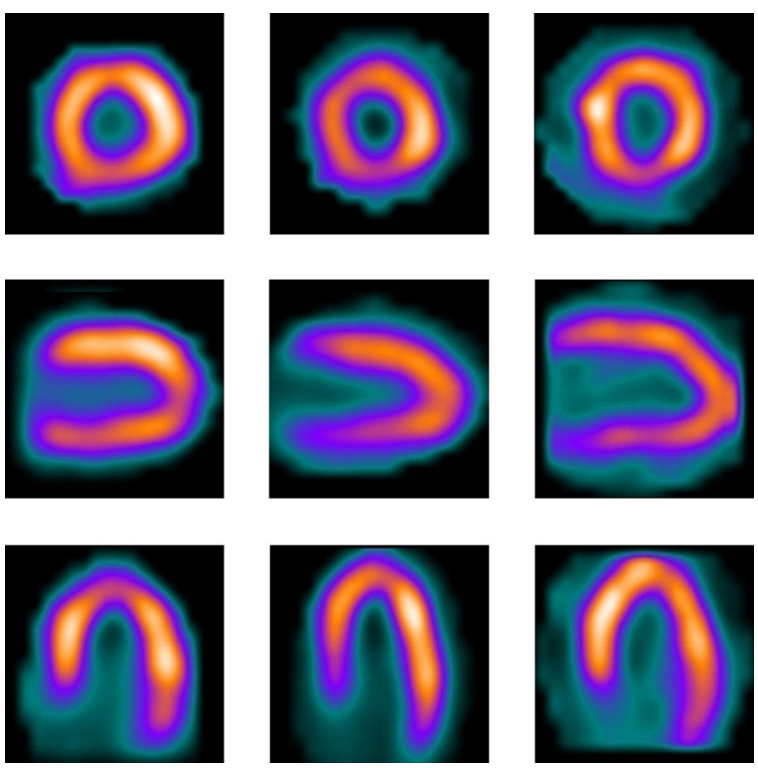

Figuer 1. Example of constant image quality in MPI SPECT scans of three male patients without any perfusion defects with varying body weights. From left to right: $66 \mathrm{~kg}\left(22.6 \mathrm{~kg} \cdot \mathrm{m}^{-2}\right)$, $85 \mathrm{~kg}\left(25.1 \mathrm{~kg} \cdot \mathrm{m}^{-2}\right)$, and $124 \mathrm{~kg}\left(34.0 \mathrm{~kg} \cdot \mathrm{m}^{-2}\right)$. The corresponding short, vertical long and horizontal long axes are shown from top to bottom. A patient-specific tracer activity was applied (330, 395, and $555 \mathrm{MBq}$, respectively), using a fixed scan time. The image quality of all three sets was scored as 'good,' independent of patients' size.

asked by telephone when booking appointments. Second, the activity or scan time must be calculated or derived from an activity-scan-time table and applied to the preparation process of the MPI study.

\section{CONSIDERATIONS}

Prior to introducing patient-specific protocols in clinical practice the following must be considered. First, when using a 1-day stress-first protocol, the administered activity for rest imaging should be more than 2-3 times the stress activity with a delay of 0.5-4 hours between both tracer activity administrations, to allow for sufficient decay of myocardial activity. ${ }^{4,5}$ A 2-day protocol prevents this problem and allows the use of identical patient-specific stress and rest activities (when using identical scan times). This will lower the rest activity and, hence, radiation dose, for these patients by a factor 2-3. The use of 2-day protocols can be considered in heavy patients, to reduce the overall radiation dose for both patients and staff. Second, a higher correction factor might be beneficial in patients weighing over $130 \mathrm{~kg}$. However, due to the low number of patients weighting over $130 \mathrm{~kg}$, we were unable to reliably extrapolate the given protocol for these patients. Third, it may be logistically difficult to obtain a variable 

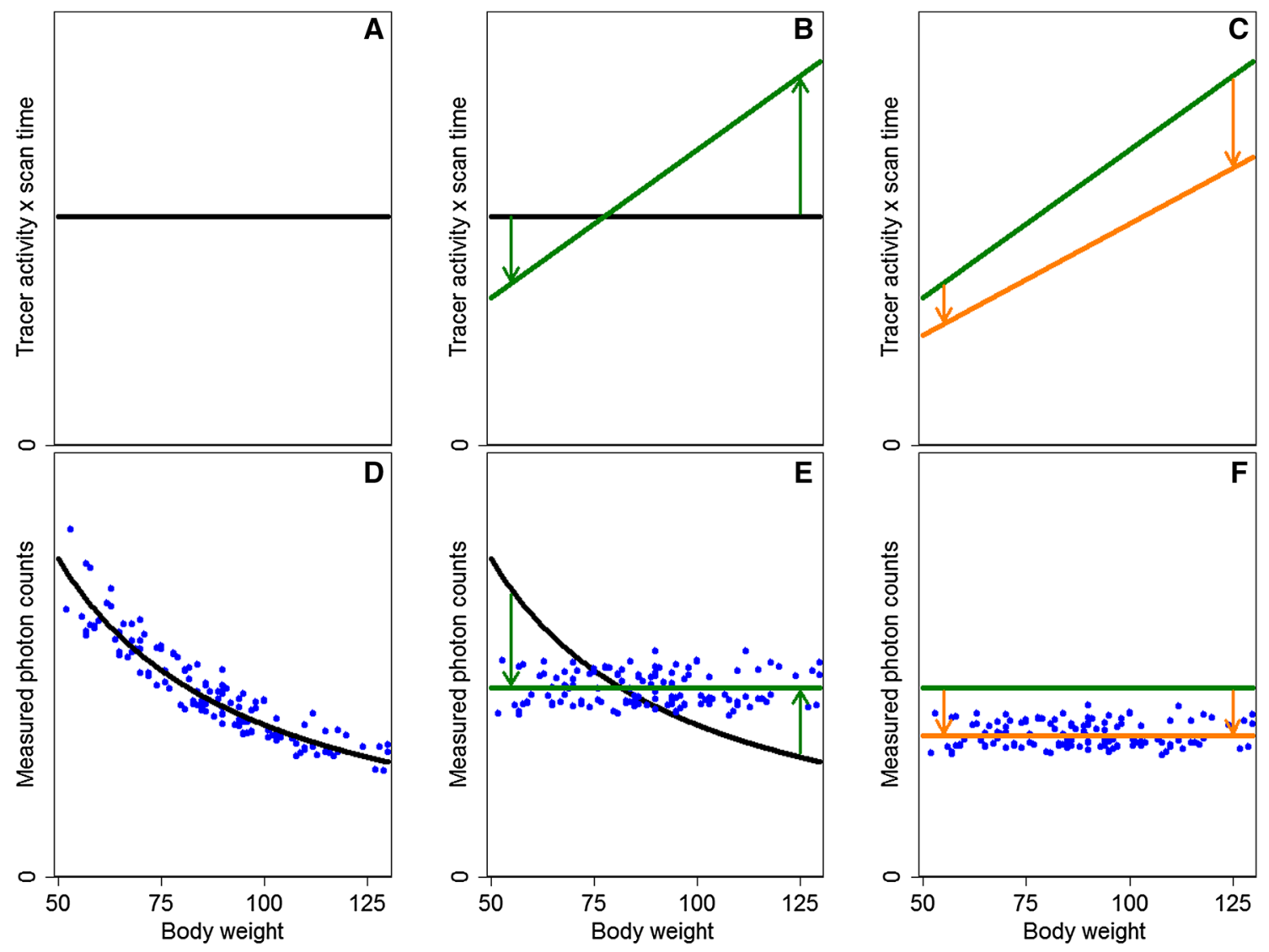

Figure 2. Schematic overview of the transition from a fixed tracer activity and scan-time product $(\mathrm{A} \times \mathrm{T})$ to a minimized patient-specific $\mathrm{A} \times \mathrm{T}$. From left to right: a fixed $\mathrm{A} \times \mathrm{T}(\mathrm{A})$ resulting in a decreasing number of photon counts and image quality for heavier patients (D). Introduction of a patient-specific $\mathrm{A} \times \mathrm{T}(\mathbf{B})$, resulting in a constant number of measured photon counts $(\mathbf{E})$. This allows to perform the final step of minimizing the patient-specific $\mathrm{A} \times \mathrm{T}(\mathbf{C})$ while maintaining the diagnostic accuracy (F). The dots represent fictitious data.

Table 1. Multiplication factors to adjust the tracer dose or scan time per projection angle as a function of patient's weight, using Eq. 1b. Furthermore, two examples for introducing either a patient-specific tracer activity or scan-time protocol are shown, using a scan time of 20 seconds per projection angle (using 32 projections) or a standard tracer activity of $370 \mathrm{MBq}$, respectively

\begin{tabular}{lccc}
\hline $\begin{array}{c}\text { Body } \\
\text { weight }\end{array}$ & $\begin{array}{c}\text { Multiplication } \\
\text { factor }\end{array}$ & $\begin{array}{c}\text { Patient-specific activity in MBq } \\
\text { using a fixed scan time of } \\
\text { 20 seconds (mCi) }\end{array}$ & $\begin{array}{c}\text { Patient-specific scan time } \\
\text { seconds) using a fixed activity of } \\
\text { 370 MBq (10 mCi) }\end{array}$ \\
\hline 60 & 0.83 & $307(8.3)$ & 17 \\
70 & 0.92 & $340(9.2)$ & 18 \\
80 & 1.00 & $370(10.0)$ & 20 \\
90 & 1.08 & $400(10.8)$ & 22 \\
100 & 1.15 & $426(11.5)$ & 25 \\
110 & 1.23 & $455(12.3)$ & 26 \\
120 & 1.30 & $481(13.0)$ & 27 \\
130 & 1.36 & $503(13.6)$ & \\
\hline
\end{tabular}




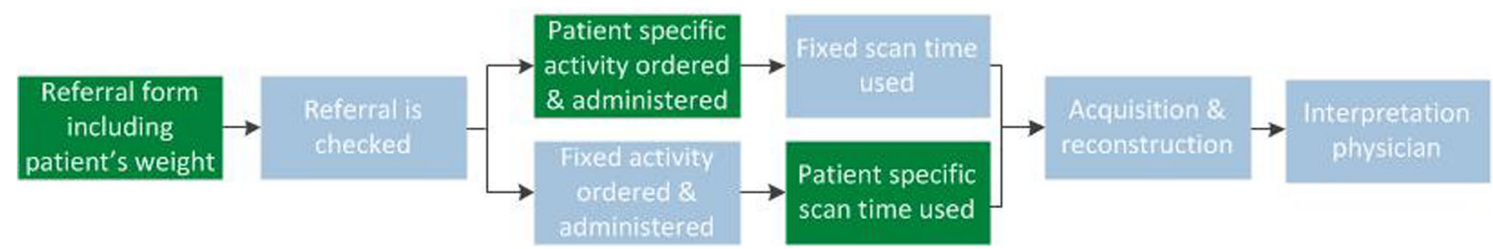

Figure 3. Schematic overview of the required planning and actions to perform when using a patient-specific tracer activity or scan-time protocol. The additional actions that are required as compared to the fixed activity era are indicated in green. The MPI-SPECT referral form including patient's body weight should be checked by a nuclear medicine physician or asked by telephone when booking appointments. Next, either a patient-specific activity should be ordered or a patientspecific scan time should be applied. Subsequently, physicians interpret the reconstructed study and determine whether additional rest imaging is necessary.

patient-specific tracer activity for a rest study after the interpretation of the stress scans using a 1-day stress-first protocol. If obtaining variable tracer activities on short notice is difficult, patient-specific scan times (and fixed tracer activity) can be applied alternatively. This, however, may slightly interfere with camera time planning. Fourth, as mentioned above, the shown formulas are a simplified approach and only eligible for conventional SPECT cameras. A different relation between measured photon counts and weight was observed using the newest generation cadmium zinc telluride based SPECT cameras. ${ }^{3}$ Hence, a different activity or scan-time correction should be applied for these scanners.

\section{Open Access}

This article is distributed under the terms of the Creative Commons Attribution 4.0 International License (http://crea tivecommons.org/licenses/by/4.0/), which permits unrestricted use, distribution, and reproduction in any medium, provided you give appropriate credit to the original author(s) and the source, provide a link to the Creative Commons license, and indicate if changes were made.

\section{References}

1. van Dijk JD, Jager PL, Ottervanger JP, de Boer J, Oostdijk AHJ, Slump $\mathrm{CH}$, et al. Development and validation of a patient-tailored dose regime in myocardial perfusion imaging using conventional SPECT. J Nucl Cardiol. 2015. doi:10.1007/s12350-015-0246-9.

2. Notghi A, Sundram FX, O'Brien JW, Smith NB. Assessing the effect of increasing injection activity for myocardial perfusion imaging in overweight patients. Br J Radiol. 2008;81:730-4.

3. van Dijk JD, Jager PL, Mouden M, Slump CH, Ottervanger JP, de Boer J, et al. Development and validation of a patient-tailored dose regime in myocardial perfusion imaging using CZT-SPECT. J Nucl Cardiol. 2014;21:1158-67.

4. Holly TA, Abbott BG, Al-Mallah M, Calnon DA, Cohen MC, DiFilippo FP, et al. Single photon-emission computed tomography. J Nucl Cardiol. 2010;17:941-73.

5. Hesse B, Tägil K, Cuocolo A, Anagnostopoulos C, Bardiés M, Bax $\mathrm{J}$, et al. EANM/ESC procedural guidelines for myocardial perfusion imaging in nuclear cardiology. Eur J Nucl Med Mol Imaging. 2005;32:855-97.

6. van Dijk JD, Jager PL, Ottervanger JP, Slump CH, de Boer J, Oostdijk AHJ, et al. Minimizing patient-specific tracer dose in myocardial perfusion imaging using CZT SPECT. J Nucl Med Technol. 2015;43:36-40. 